\title{
Gesturing Towards Definition: Passing Thoughts on Lack and the Phallus
}

\section{Susannah Bredenkamp}

The problem of defining masculinity has plagued masculinity studies since its inception. Attempts at definition have been seen as either too vague, incomplete, or unable to account for the way men live and experience masculinity. This paper explores these difficulties and the problems of a 'content-based' definition of masculinity. I trace the way in which people seek to 'pass' as masculine and the origins of masculinity in nineteenth-century studies of biological difference. I argue that masculinity must be defined discursively, and that this definition bears striking similarities to Lacan's concept of the phallus. I argue, further, that masculinity, as it is lived, is a state of hybridity, the result of colonization by the phallus.

The difficulty of defining masculinity is widely discussed within masculinity studies. Jeff Hearn notes the "variety of uses of the concept, [and] the imprecision of its use in many cases," while Kenneth Clatterbaugh writes that it "may well be the best-kept secret of the literature on masculinities that we have an extremely ill-defined idea of what we are talking about." ${ }^{2}$ One solution to this problem would involve understanding 'masculinities' as the varieties of gender expressions of men, a move which avoids the need to define the content of masculinity. For this reason, Hearn has suggested that it would be more appropriate "to base analysis on the concept of 'men' and what men do or think or feel," thereby taking the focus away from 'masculinity' altogether. ${ }^{3}$ Similarly, Clatterbaugh argues that the term 'masculinities,' as it is used in masculinity studies, is a "subterfuge," which is already a way to talk about men, and that an acknowledgement of this fact (in view of our inability to agree on a definition of 'masculinity') would "at least guard against the further mystification of it."s From a feminist perspective, I must wonder whether anything new may be gained by speaking of the experiences of men in this way, and especially whether the analysis of men's experiences in the context of masculinity studies does not serve to reinscribe masculinity as a natural, yet unexamined, domain accessible only by certain (privileged) male bodies.

It is not necessarily problematic to study gender in relation to male bodies or to study the way that men 'do' gender. What is problematic is the association, however implicit, between male bodies and masculinity. This association runs the risk of misunderstanding the gender expression of feminine homosexual men, male-to-female transgendered persons, and men who are androgynous. In the context of 'masculinity,' these gender expressions by or through male bodies can be seen as a failure. To attempt to subsume these men and their gen- 
der expressions in a study of men's experiences, or within the range of 'masculinities' expressed by male bodies, is to force an understanding of the people in question which they may not hold of themselves; when these people may not think of themselves as masculine, or even male. Taking the focus away from masculinity, and placing it on 'men,' also fails to account for and address the feminization of black men, ${ }^{6}$ Jewish men, ${ }^{7}$ and other "adjectival masculinities" throughout history. Discussing the gender expressions of black or Jewish men in the context of 'men's experiences' or 'masculinities' allows us to forget that black and Jewish male bodies were seen as inferior, feminized, and not really male until well into the twentieth century. It was not a failure to live up to a white, Anglo-Saxon, heterosexual standard of gendered behaviour that was at issue in the association of these men with femininity or the female. On the contrary, it was a failure of the body itself - a failure to live up to 'maleness.' Viewed in this way, de-emphasizing 'masculinity' in an attempt to focus on the male is not, as Clatterbaugh suggests, a de-mystification at all. There is an unexamined assumption here that we know what 'male' is, what a man is, and it is an assumption which fails to take into account the mutually constitutive relationship between gender and the body, especially as it is demonstrated in the excellent work done within current gender theory ${ }^{9}$ and by feminist deconstructionists in biology ${ }^{10}$ and the history of science." The consequence of the continued mystification of 'maleness' is not only the exclusion of "female masculinity"12 from the study of 'men's behaviour,' but also the erasure of intersexuality. ${ }^{13}$

The final criticism of studying men returns us to the need for a definition of masculinity. If we recognize that gender expression is not necessarily tied to biological/morphological sex and that we do not only lack a definition of masculinity, but that our understanding of 'maleness' is historically and culturally specific, i.e. that the bodies of homosexual men, Jewish men, black men and others have not always been included in the category 'male,' then we are forced to consider the relationship between masculinity/maleness and the way in which power (whether political, economic, scientific-discursive, or social) is distributed and accessed. In short, if certain rights and kinds of access have been denied to a variety of classed, raced, and sexed bodies based on their failure to approximate either maleness or masculinity, then to know the definition of masculinity is to know the condition of access to power. Further, if much of the work in masculinity studies has focused on what Clatterbaugh calls 'adjectival masculinities,' such as 'Jewish ... Black ... Chicano ... [and] gay masculinit[ies]," ${ }^{14}$ we must ask what makes these masculinities 'adjectival?' How do we know that they are 'alternate' examples of masculinity at all, if we have no definition of masculinity? And, most importantly, is the designation of these 'masculinities' as adjectival or alternative not just another way of prohibiting access to 'true'/non-adjectival masculinity or maleness? 
The most influential definition of masculinity, and also the most widely cited and debated ${ }^{15}$ within masculinity studies, is R. W. Connell's formulation. According to Connell, "hegemonic masculinity ... is the configuration of gender practice which embodies the currently accepted answer to the problem of the legitimacy of patriarchy [and] which guarantees (or is taken to guarantee) the dominant position of men and the subordination of women." ${ }^{116}$ Connell goes on to say that hegemonic masculinity is not necessarily embodied and that the bearers of hegemonic masculinity "may be exemplars, such as film actors, or even fantasy figures, such as film characters." Edley criticize Connell's definition, based on the fact that "the impossibility or fantastic nature of hegemonic masculinity is one of its defining features." They write that the definition is "vague" and "imprecise"19 and does not tell us anything about how men live masculinity. Connell himself seems unclear about the relationship between his definition and masculinity as it is lived, or, rather, power as it attaches to bodies as a consequence of masculinity. He writes that "it is the successful claim to authority ... that is the mark of hegemony," but adds: "this is not to say that the most visible bearers of hegemonic masculinity are always the most powerful people" and that "individual holders of institutional power or great wealth may be far from the hegemonic pattern in their personal lives. ${ }^{20} \mathrm{He}$ insists that men who do not live up to the definition still reap the benefits of hegemonic masculinity, but also that some men are subordinated by other men, because of hegemonic masculinity. ${ }^{21}$ This is a lot of work for one definition to do: how is hegemonic masculinity a 'gender practice' if it is nowhere embodied? More importantly, if the embodiment of hegemonic masculinity is not a guarantee of power and, conversely, power is not wielded only by those who are hegemonically masculine, how is it possible that the successful claim to authority is the mark of hegemony? Further, if some men reap the benefits of patriarchy without embodying hegemonic masculinity, yet masculine embodiment is not the factor that distinguishes between the beneficiaries and the subordinated, how does hegemonic masculinity guarantee the dominant position of men (over women or other men)? These are the questions with which this paper seeks to engage.

It is worth acknowledging that a variety of different behaviours, traits etc. may be valorized, validated, supported or encouraged within any given subculture or section of the population, and may be called 'masculinity' within a given group. The differences in behaviour which are expected from people who are seen to be morphologically and/or biologically male may well range, for example, from scholarly intellectualism to brute strength and athleticism. Any number of other factors might form the basis for judging whether an individual is 'masculine' (or, more accurately, whether they are behaving in an ideal or appropriate way for someone who is perceived to be 'male') within their own profession, class, or community (be that based on location, religion, ethnicity, 
interest etc.). Whether or not these 'masculinities' are experienced as complete and functional within these communities, how they are supported or perpetuated and how they translate outside of their contexts is not the focus of this article. There has been extensive research done within masculinity studies on this topic, typically from a cross-cultural, sub-cultural, post-colonial or historical perspective and typically talking about 'masculinities' or 'alternative masculinity. ${ }^{22}$ The problem that I mentioned in my introduction, however, still persists: in upholding the notion of 'masculinities,' 'alternative masculinity' or 'masculinity' (as it is lived) as somehow distinct from or contrary to the unattainable hegemonic masculinity, we are in danger of accepting that any behaviour which is exhibited by, or expected from men is 'masculine.' This acceptance rests on an assumption that we know what a man is and that there is a necessary relation between 'maleness' and 'masculinity.' Moreover, it leaves the biological/morphological category 'male' unexamined and makes it the foundation for 'masculinity' (i.e. we know that the behaviour is 'masculine,' because the body is 'male'). It is my belief that this kind of passive analysis brings us no closer to an understanding of masculinity.

\section{Passing}

Connell's definition of hegemonic masculinity is based on the function of the term (to legitimate patriarchy and subordinate women), but it tells us nothing about the content of hegemonic masculinity. Michael Kimmel, in an attempt to expand on Connell's definition, cites Erving Goffman's definition of the "one complete, unblushing male" in American culture: "a young, married, white, urban, northern heterosexual, Protestant father of college education, fully employed, of good complexion, weight and height, and a recent record in sports...." ${ }^{23}$ This is not, however, the definition that men give of masculinity, when asked to describe it. Wetherell and Edley, in a study which explored Connell's definition, asked men to define masculinity and to discuss the extent to which they embodied their own definition. They found that men defined masculinity in the stereotypical ways "usually attributed to hegemonic masculinity (strength, boldness, winning challenges...),", ${ }^{24}$ but that this definition was "not the principal method by which the men interviewed constructed themselves as masculine."25 As Clatterbaugh notes, "masculinity ... is identified with the stereotype or the norm ... [but] the obvious difficulty in talking about ideas and norms is that we are not talking about actual traits; we are talking instead about beliefs about these ..."26 and not about gender roles. It is to be wondered whether the stereotypical definition of hegemonic masculinity is a definition of masculinity at all, if it has no bearing on whether people see themselves as masculine and if it cannot function as a standard which allows us to judge whether someone is masculine or not. Clearly, a different approach to the 
project of definition is needed, so I will approach the problem through the process known as 'passing.' If people who believe themselves to be masculine are simultaneously unable to explain why or how they are so, 'passing' allows us to see what people who are not sufficiently male/masculine have to do in order to succeed at masculinity. As Sara Ahmed writes, passing renders identity as the following:

[an] object that can be known, seen and approximated. If I desired to pass for a particular other, I can imagine myself saying: 'Look, this is what you are, so I will become you. I will move, talk, eat, smell and be like you. By adopting your dress and manner, I will pass for you.' The subject who seeks to pass may assume the knowability of the place of the other. ${ }^{27}$

It is therefore in the place of the 'other' that I will begin my search for the definition of masculinity.

Passing, Elaine K. Ginsberg notes, "has been applied discursively to disguises of ... elements of an individual's presumed 'natural' or 'essential' identity, including class, ethnicity, and sexuality," ${ }^{28}$ but its specific origins lie with race, specifically with "the discourse of racial difference and ... the assumption of a fraudulent 'white' identity by an individual culturally and legally defined as 'Negro' or black." ${ }^{\prime 29}$ As such, racial passing is usually understood as possible only when someone who is legally black has a skin tone light enough to prevent the visual discovery of their 'true' race. In this way, passing is made possible through "the false promise of the visible as an epistemological guarantee" ${ }^{30}$ and necessitates a "face, voice, skin color [and] body type ... that defies or confounds easy profiling." ${ }^{31}$ According to this view, the only way for someone who is black to pass as white is to actually be white (physically, if not legally), but passing, it turns out, is more complex than that.

Frantz Fanon wrote that "the black is not a man ... the black is a black man. ${ }^{\prime 32}$ This statement clearly illustrates that the state of being 'adjectival' with respect to maleness or masculinity is not merely one of difference, but of inferiority. Because of his race, the black man is not seen as being completely and unproblematically male. It would follow, then, that passing as a man would only be possible through becoming literally white, through the circumstance of being born with light skin. With respect to a definition of masculinity, we can say that hegemonic masculinity is always white. However, Fanon's extended meditation on the topic, in Black Skin, White Masks, has more to tell us about how to pass as white, and therefore male. "The Negro of the Antilles," he writes, "will be proportionately whiter-that is, he will come closer to being a real human being - in direct relation to his mastery of the French language." ${ }^{33}$ A black man may also be "white above a certain financial level" 134 and "one is white as one is rich, as one is beautiful, as one is intelligent." ${ }^{35}$ Fanon relates 
one incident when he managed to 'pass,' despite his skin colour, based on his success in one of these areas:

Rather more than a year ago in Lyon, I remember, in a lecture I had drawn a parallel between Negro and European poetry, and a French acquaintance told me enthusiastically, 'At bottom you are a white man.' The fact that I had been able to investigate so interesting a problem through the white man's language gave me honorary citizenship. ${ }^{36}$

I am not suggesting that Fanon's display of intelligence and eloquence on an academic topic had caused his acquaintance to forget that he was black, or even that his blackness had ceased to matter. In that moment, however, the colour of his skin became less salient in his acquaintance's reading of his identity. Through an exceptional display of the characteristics typically associated with white masculinity, Fanon's blackness ceased to be the determining feature of his 'essence'-in that moment he was only black because of his skin colour and, but for his skin colour, he was a (white) man. Richard Dyer notes that reference to a truer or deeper white essence is a common practice when distinguishing a black man who 'passes' because of his eloquence or intelligence (i.e. his 'white' behaviour or character), from other black people: "Bastide provides a striking example ... when a Negro is accepted, one often says, in order to separate him from the rest of his race, 'He is a Negro, of course, but his soul is white." ${ }^{37}$ Fanon sees this kind of passing, despite visibility, as a kind of contract. In a discussion of Rene Maran's Un homme pareil aux autres, Fanon notes that the black man who passes is asked to agree to "one condition":

\footnotetext{
"You have nothing in common with real Negroes. You are not black, you are "extremely brown." This procedure is quite familiar to colored students in France. Society refuses to consider them genuine Negroes. The Negro is a savage, whereas the student is civilized. 'You're ' $u$ ' '... and if anyone thinks you are a Negro he is mistaken, because you merely look like one. ${ }^{38}$
}

In this way, the 'white' characteristics displayed by the black man remain 'white' characteristics. The black man who succeeds at defying the expectations people have held of him based on his race is not even taken as an 'exceptional' example of blackness. Instead, his visibility as black is supplanted by a deeper and more essential 'whiteness'-which accounts for his departure from racial stereotypes-thereby leaving those stereotypes intact. It is for this reason that I wish to insist that the process I have been describing is, however counter-intuitively, 'passing.' That it is, in effect, passing in full view. Based on this discussion of passing by black men, we can add not only whiteness but also wealth, an eloquent command of language, and high intelligence to the definition of hegemonic masculinity. These are the features which may allow a 
black man access to full personhood, to a non-adjectival maleness or masculinity.

Jewish men have long been associated with a constitutional femaleness. Sander L. Gilman shows how nineteenth- and early-twentieth century accounts of the Jewish character drew from simultaneously circulating stereotypes about women, such as having "no sense of humour," exhibiting "a want of depth" and being "materialistic." more than behavioural. Jewish men were believed not only to be prone to 'female' diseases, such as hysteria, ${ }^{40}$ but were also thought, until the seventeenth century, to menstruate. ${ }^{41}$ In this case, 'passing' by Jewish men is akin to a transgender or transsexual passing-passing from a purported female embodiment to that of the male. Athleticism is one way in which this is accomplished, but, paradoxically, this is not because of their supposed femininity, but because of an overwhelming intellectuality. Where intellectualism allows Fanon, as a black man, at least a contextual access to hegemonic masculinity, it precludes it for the Jewish man. Gilman describes how the stereotype of the intellectual, and therefore physically weak, Jew was attributed by Jewish psychiatrists in America in the 1920 s to 'social' rather than 'biological' heredity, and resulted in an attempt to produce the "all-American athlete" through

sports and play ... [which] form an incomparable avenue of discharge for nervous tension ... [Psychiatrists added that] circumstances excluded the Jew from their wholesome influence, and the children of the race grew up to be very serious, very earnest, too early devoted to mature efforts, excessively cerebral in their activities, and not sufficiently strenuous physically. ${ }^{42}$

This stereotype is still in existence, as Bornstein notes: "intellectual Jewish boys like me who were clumsy, fat and not good at sports were not 'real' boys, not in the Christian All-American community I grew up in." ${ }^{43}$ The very physical ability that defines the black man, dissociates him from intellectuality, and keeps him from accessing hegemonic masculinity allows the Jewish man entry into that same category. It would be inadequate to conclude that hegemonic masculinity involves both a degree of athleticism and a degree of intellectuality (although this is undoubtedly so). What we should realize, based on a comparison of the two kinds of passing discussed thus far, is that a mere listing of the traits associated with hegemonic masculinity does not produce a satisfactory definition. We still do not know to what degree someone needs to possess or exhibit a specific trait in order to qualify as 'masculine' or what balance of these traits constitutes the ideal. Further, it seems that access to masculinity as based on these traits is differential. A black man who displays any athleticism puts his intellectuality and his masculinity in question, while a Jewish man who displays intellectuality runs the same risk. What it takes to succeed or pass as male is 
based not on living up to a standard but is the result of a negotiation between each particular body and its perceived or attributed lack.

I have not been concerned, in my discussion of passing by Jewish men, with the modification of physical c(l)ues. There have, of course, been many attempts to describe the physical markers of Jewishness, ${ }^{44}$ but, for the purposes of this paper, I am more interested in the fact that these attempts have often failed. Dyer writes that Gilman

\begin{abstract}
details the tradition of representing Jews in terms of physiognomic difference, including skin, eye and hair colour. However, as he notes, there was a countervailing tendency, which argued that Jews in fact varied in appearance according to geography. Scientists began to demonstrate that Jews were 'the adaptive people par excellence' (1991: 177). Already in 1787 Samuel Stanhope had argued thus: 'In Britain and Germany they are fair, brown in France and in Turkey, swarthy in Portugal and Spain, olive in Syria and Chaldea, tawny or copper-coloured in Arabia and Egypt. ${ }^{, 5}$
\end{abstract}

It is for this reason that the very ease with which Jews were supposed to pass became inscribed as a marker of biological difference. Daniel Itzkovitz writes that the "notion of shape-shifting and the performance of an identity other than 'one's own" became a characteristic of Jewish difference in the early twentieth century. "Jews, it was commonly claimed, were a 'chameleonic race' whose veins coursed with ... "strange chameleonic Jewish blood." "46 The "use of 'blood' (in the phrase 'chameleonic blood')," Itzkovitz notes, "betrays a desire common to many writers of the period to fix the Jew by using a discourse of difference that would posit Jewish identity as somehow essential and immutable ... [but] the most common 'fixation' of Jewishness was accomplished, paradoxically, through the notion of chameleonism." "This meant that "the Jew was most Jewish ... when not Jewish" of the Jew is in passing." 49 This is a notion that completely overturns any common-sense understanding of passing. Brooke Kroeger writes that "it is passing when people effectively present themselves as other than who they understand themselves to be. Effectively is the key, because an ineffectual effort to pass is just that, a failed attempt." ${ }^{0}$ In the case of Jewish passing, this is not at all true. While visibility, in Fanon's case, did not preclude his passing, in the Jew's case, invisibility does not guarantee successful passing. Passing is, in fact, the marker of Jewish difference and identity - rather than its successful concealment. I will return to this paradox, and its consequences for a definition of masculinity, at a later stage.

If the requirements of hegemonic masculinity are always to be discerned in relation to an individual's own lack (albeit attributed through any number of stereotypes), and if passing is the way in which that lack is either hidden or 
made less salient, then FTM (female to male) passing should be especially illustrative in defining masculinity. Who, after all, would have more to conceal, more physical cues to modify, and a greater distance to traverse toward 'maleness' than someone who is biologically female? Perhaps, on the other hand, the problem of FTM passing appears as a relatively simple one: hide the obviously female body parts successfully and passing is accomplished. Passing, as we have seen, however, is rarely that simple. Intellectualism, rather than race, provided a means for black men to pass, while athleticism performed the same function for Jewish men. Similar processes are at work in FTM passing. As is to be expected, much of what is required for FTMs to pass involves the modification of physical cues. My discussion of FTM passing draws on suggestions compiled at a website entitled "FTM Passing Tips." flatter chest is an important part of presenting as male" and that "many women have light-coloured 'peach fuzz,' but men don't, so shave it off." In addition, it is important to "make sure your trousers fit low and aren't tight- this helps to hide both your hips and your waist." Passing is also aided by "wearing tall shoes, or shoes with lifts" and "bodybuilding [which] can make a difference in getting your body to take on a more male shape." ${ }^{52}$ Height and a reasonable degree of musculature, then, are also part of what constitutes physical maleness. It is certainly true that women are, on average, shorter than men and that bodybuilding can broaden shoulders and narrow hips, thereby concealing femaleness. On the other hand, it is clearly an ideal male body which is approximated here. Being short and lacking muscle are circumstances which make passing more difficult—as with Fanon's intellectuality, an extreme demonstration of the hegemonic ideal is required in order to pass. The indisputable performance of hegemonic maleness is, at least when clothed, defined physically by a flat chest, tallness, and muscularity.

The modification of physical cues is only a small part of FTM Passing. In terms of hairstyle and dress, the website advises methods which emphasize a conservative or middle-class self-presentation: "go for a short back and sides cut, but avoid getting an all-over crewcut or 'punk' style ... ask for a 'traditional men's cut," and "dress more conservatively-you might want to leave the motorcycle jacket at home for a while." ${ }^{3}$ Instead, FTMs should "start with an ironed button-down shirt, worn with pressed khakis, dress slacks, or neat-looking blue or black jeans" and "ties are, of course, a great way to pass." Masculinity is middle-class and, in the case of FTMs, it is, again, an extreme version of the ideal which facilitates passing. In a discussion of perhaps the most famous case of FTM passing, that of Brandon Teena, Judith Halberstam writes that Brandon's self-presentation must be read ... as a damaging critique of the white working-class masculinities around him ... His performance of courtly masculinity [was] a shrewd deployment of the middle-class and socalled 'respectable' masculinities that represent an American romantic ideal of 
manhood." ${ }_{55}$ Ginsberg notes that "Brandon's passing was convincing enough that, even after the local law enforcement officers and some angry men exposed him, both legally and literally, women still insisted that he was "one of the nicest men' they had ever met and the 'best boyfriend' they had ever dated." $\$ 56$ Halberstam clearly attributes this success, at least in part, to Brandon's performance of middle-class masculinity. As in the case of black passing, where race is made less salient by intellectuality, here sex is made less salient by class.

In addition to a tall, muscular body and a middle-class identity, hegemonic masculinity can be defined by a vague category of behaviour which I will call "deportment." Kroeger writes that "passers make an art of appearing in all respects - speech, gestures, attitudes, conversation, mannerisms, expressions, associations, interests, apparent lifestyle and dress." ${ }^{57}$ In order to manage these various cues, FTMs are advised (again through the "FTM Passing Tips" site) that "women tend to use an upward inflection at the end of their sentences, while men tend to speak in more of a monotone" and that "women tend to be less obtrusive, while men tend to take up more space." Specific instructions are included on the use of bathrooms: "just march calmly in, use the stall, and march calmly out ... don't talk to anyone, don't make eye contact, and whatever you do, don't try to look at anyone's dick. ${ }^{\prime 58}$ Handshakes, also, require specific instructions: "make them firm, not like a dead fish. Lock your thumb into the other person's hand and look them in the eye. Don't pump excessively." 59 These are, of course, instructions that many men would at once recognize as implicit in their daily behaviour and interactions, and which might also be so intuitive that they are never even thought about. The point of examining FTM passing is to note that these are learned behaviours which are crucial in the successful performance of masculinity, regardless of how much they have become second-nature to men who do not have to learn how to be men during adulthood. It may seem silly to add the injunction "if you see a guy in a bathroom, don't make eye contact. If you shake his hand outside, do" to a definition of hegemonic masculinity, but it is precisely the details of deportment-how you carry yourself, how you speak, how firm your grip is when you shake someone's hand - that can make or break the performance of masculinity. A "large part of passing," the FTM Passing Tips site notes, "is sheer confidence and bravado. If you really believe you're a man and project this belief to the rest of the world, it will go a long way towards also convincing others. Any difficult feature you might have (high voice, smooth face, small shoulders, wide hips, lack of height, etc.) is one that some non-trans men have also-there are even non-trans men with enlarged chests (male gynecomastia)." ${ }^{\prime 60}$ Deportment, then, is the variable which makes masculinity especially difficult to define, especially when the behaviour required in one context is exactly the opposite from what it is in another. It would take an exceptionally long list to describe every context in which a man might find himself, and the exact behaviour required of him 
in that moment, and it is to be expected that most men will have failed to perform the right behaviour at the right time at least once. We would have to conclude that hegemonic masculinity is not only difficult to define because it requires different behaviour from different people (the degree of intellectuality or athleticism men should demonstrate), but also because it requires different behaviour from the same people at different times in their lives and in different contexts. ${ }^{61}$ To further complicate the problem of definition, FTM passing also shows that the behaviour which might be called 'masculine,' when exhibited by a man, may in fact be the same behaviour a woman exhibits under a different name. Dean Kotula, in his book The Phallus Palace, includes personal accounts by a number of post-operative transsexual men. One such man writes about the difference in people's perceptions of his behaviour as a woman and (post-transsexual surgery) as a man: "now, although my behaviour has changed little, people are far more accepting of me. The same behaviour that people once labelled 'brusque, 'distant' or 'superior' is now interpreted as 'direct' and 'assertive." "'62 A display of 'masculine' behaviour, in this case, does not aid in passing and, by extension, we might wonder whether the behaviour itself can properly be called masculine, if it is only interpreted as such in the context of certain readings of the body. A definition of masculinity would have to account for the interplay between the body and gendered behaviour - the body must be understood, not as separate from gender, and certainly not as the cause or origin of gendered behaviour, but as a performance which informs the reading of gender.

The disabled body, Rosemarie Thomson notes, has historically been associated with the female: "perhaps the founding association of femaleness with disability occurs in ... Generation of Animals, Aristotle's discourse of the normal and abnormal ... In Book Two, Aristotle affirms [the] connection of disabled and female bodies by stating that 'the female is as it were a deformed male." "' ${ }^{63}$ In a study of 1920 s print advertising, Harlan Hahn finds that the conflation of disability and the female "even permitted the belief that a male seated in a wheelchair was not really a man." ${ }^{.64}$ Passing, for men with disabilities, is again a matter of transcending the female/"other' body and successfully performing 'maleness.' Lennard Davis notes that Antonio Gramsci, George Byron, Jorge Luis Borges and James Joyce all had disabilities, but "when one looks up these figures in dictionaries of biography ... their physical disabilities are usually not mentioned ... There is an ableist notion at work here that anyone who creates a canonical work must be physically able." conceived by the nondisabled world, has no abilities or social functions [and] ... those who do perform successfully are no longer viewed as disabled." ${ }^{\prime 6} \mathrm{We}$ might, then, add great success as one of the features on the ever-growing list of items which should be included under 'hegemonic masculinity.' Success is, in fact, so salient a feature of masculinity that it can erase disability altogether, 
while passing, as a daily matter of "keep[ing] up ... [and not] taking too much sick time," ${ }^{\prime 67}$ results, as with blackness, in a decrease in the saliency of one's identity as 'other.' Candice Lee writes: "I can't tell you the number of people who say, 'I just don't see you as disabled,' or 'I had met you three times before I noticed your braces' ... I'm just a person, like them. Therefore, I must not be disabled. Not really." ${ }^{98}$ It is not to be imagined, however, that disability is so easily overlooked. Although Connell is clearly right in suggesting that the people who wield great power may be far from the hegemonic ideal in their private lives, this is accomplished either because the person's disability is not visible (when, for example, we read a book they have written), or, as in the case of $F$. D. Roosevelt, because the visual aspects of disability are very carefully managed. Davis relates in detail how Roosevelt, disabled by polio, made sure never to be photographed in a wheelchair, or to be seen being carried up stairs or using crutches. ${ }^{69}$ On one occasion

when Roosevelt was being lifted out of a car, some newsreel cameramen were filming the event and Roosevelt said, 'No movies of me getting out of the machine, boys.' The Secret Service would intervene if any photographers attempted to take such photos, and they would seize and expose the film. This was official government action to erase any visual trace of the President's disability. ${ }^{90}$

This is obviously an extreme example of the way in which (a great deal of) power and success allowed one man to manage his performance of hegemonic masculinity, regardless of how 'un-hegemonic' his embodiment was in private. In fact, his encounter with polio and rehabilitation was characterized as a "triumph over physical disability"-making Roosevelt's public self-presentation arguably more hegemonic than that of a man who had never proven himself capable of mastering his body to such a degree. ${ }^{71}$

My reading of passing, thus far, has contributed the following items as definitive of hegemonic masculinity: it is white, Christian/Protestant, intellectual, athletic, 'healthy'/'able-bodied,' middle-class, muscular, and tall. Thus far, Goffman's definition of the 'one, complete, un-blushing male,' cited earlier, seems like quite an accurate picture of masculinity, even if we do not know to what degree each of these characteristics must be embodied in order to qualify the whole of the performance as 'masculinity.' However, I have also shown that masculinity requires different behaviours at different times and in different contexts and that the definition becomes especially convoluted when we consider the category I have called 'deportment.' We are also faced with the problem that the body, in relation to behaviour, is sometimes salient, sometimes not, and sometimes a factor which determines how behaviour is read. Finally, the very factors, which I have been exposing as aspects of masculinity, also make 
it internally contradictory - denying masculinity to Jewish men because of having too much intellectuality, and to black men for not having enough. Davis' discussion of the visibility of disability further complicates the difficulty of definition. Davis writes,

some disabilities disappear [in the space of email]: the Deaf, for example, or people using wheelchairs with other physical limitations, are not disabled ... When speaking on the telephone with a person who uses a wheelchair I have no way of knowing if that person is unable to walk ... the Deaf are perceived as such because one hears a different speech inflection or sees sign language. Without those sensory clues, the Deaf are embedded in the sensory grid of the 'normal' person. To a passerby on the street, the Deaf person is indistinguishable from anyone else until he or she begins to engage in communication. ${ }^{2}$

Disability passing, then, gives us insight into the specificity of lack and its relationship to 'passing.' As I have noted with respect to Jewish and black passing, there seems to be a relationship between a person's purported 'lack' and what they need to do in order to pass. Davis' discussion serves to remind us that lack, itself, is more salient in some contexts than others (we would also do well to remember that some kinds of 'lack,' such as a want of athleticism, might be salient in fewer situations than others, such as race.) In the context of masculinity this is not necessarily that informative. We would probably assume that a man who felt he was not athletic enough would attempt to build muscle in order to seem more athletic, or might over-emphasize his competitiveness or aggressiveness on the playing field in order to affirm his athleticism, or might become an avid armchair enthusiast, lending his support to the local team, thereby demonstrating his commitment to such 'manly' athletic pursuits. Again, however, the performance of masculinity is not that simple. In an article entitled "Masculinity in the Age of AIDS: HIV-Seropositive Gay Men and the 'Buff Agenda," Perry Halkitis shows that a muscular, "masculine' physique can be used as a tool by some HIV-positive gay men in order to pass. ${ }^{73}$ They are not using muscularity to pass as 'masculine' or straight, however, but to pass as 'healthy,' or HIV-negative. We are faced with two further problems here: firstly, the specificity of lack does not determine what is needed to 'pass' - 'masculinity' is deployed to produce a reading of 'health'-and secondly, we can hardly consider 'able-bodied' as one of the defining features of masculinity, as a subordinate term, when one can, in fact, stand in for the other (a process we have also seen in the case of class and sex). Clearly, a different approach is required. I have, thus far, been taking a semantic approach to the problem of defining masculinity. I will turn now to a discursive approach. 


\section{Hegemonic Embodiment}

We have seen not only that being middle-class, white, intellectual, 'able-bodied,' and athletic can 'stand in' for maleness or masculinity, but that blackness, Jewishness, and disability 'stands in' for the female. It follows, then, that there is no difference that we can reasonably define semantically. An attempt to define the content of any one term will fail, not only because of the gradations which are possible within each kind of difference (there will always be someone who is taller, smarter, more athletic), nor because behaviour is contextual, and read in relation to the body. The ultimate failure of definition lies in the fact that whiteness can as easily be defined as male and middle-class, as masculinity can be defined as white and middle-class and so on. To attempt such a definition, a content-based definition, is to assert that there is one kind of difference which is prior. It is tempting to suggest that the association of certain racial/'other' male bodies with the female is a sign that sexual difference is the ground on which all of our other understandings of difference is built, but, as Thomson's reading of the female in relation to disability suggests, we could as easily map sexual difference onto a pre-existing grid of the healthy/complete body vs. the ill/mutilated body. The reality is that difference is constructed in reference to difference in a non-linear way. Robert McRuer writes that the "consolidation [of disability and homosexuality] occurs through complex processes of conflation and stereotype: people with disabilities are often understood as somehow queer (as paradoxical stereotypes of the asexual or oversexual person with disabilities would suggest), while queers are often understood as somehow disabled (as an ongoing medicalization of identity, similar to what people with disabilities more generally encounter, would suggest)." ${ }^{.74}$ If, as Dyer notes, the difference of class can be justified in relation to race ${ }^{75}$ and, as I have shown, the difference of race can be justified in relation to the female, and the difference of the female can be justified in relation to disability, and the difference of disability can be justified in relation to homosexuality, and so forth, we must allow that it is difference itself which is prior. The 'reality' of biological difference, as Dyer shows, is based only on the need for difference, and is ultimately historical and cultural. "Some people," he writes, "[such as] the Irish, Latins, Jews-are white sometimes ... For much of British history, the Irish have been looked down on as black," i.e. the biological attribution of race is written onto the body where difference is required for cultural or economic reasons. ${ }^{76}$ Thomas DiPiero, similarly, writes that "we have installed [sexual difference] in and through language as well as in and on bodies." Body, Anne Fausto-Sterling conclusively demonstrated the way in which the body was 'sexed' through science (a process I would call 'scientific sexism') in response to the demands of first-wave feminism and suffrage movements, during the same historical period when the medicalization of difference sought to 
distinguish biologically between races, classes, and cultures. Difference, or at least difference as we understand it today (with an implicit reference to "biology'), is a result of science. "In the nineteenth-century," writes Nancy Stepan, "as attention turned increasingly to sexual and gender differences ... gender was found to be remarkably analogous to race, such that the scientists could use racial difference to explain gender difference, and vice versa ... In short, lower races represented the 'female' type of the human species and females the 'lower race' of gender." ${ }^{.78}$ The use of analogy, Stepan argues, is intrinsic to biological science: "metaphors ... [are] essential to scientific thought itself." If ly wish to arrive at a conception of hegemonic embodiment, then, we should return to the history of the categorization of bodies, based on difference, during the nineteenth century.

Davis finds the answer to the question of hegemonic embodiment, not in nineteenth century biological science per se, but in the new discipline of statistics as used in relation to bodies. Davis writes that, as late as the seventeenth century, a cultural notion of the 'ideal' persisted, "as exemplified in the tradition of nude Venuses, for example. This idea presents a mytho-poetic body that is linked to that of the gods ... [and] is not attainable by a human ... [There was] no demand that populations have bodies that conform to the ideal." ${ }^{\prime 80}$ With the arrival of statistics, however, we suddenly encounter the idea of the 'normal' or average. ${ }^{81}$ In 1835 , Quetelet first noted that a method previously used in astronomy, and known as 'the law of error', could be

applied to the distribution of human features such as height and weight. $\mathrm{He}$ then took a further step of formulating the concept of 'l'homme moyen' or the average man...Quetelet's average man was a combination of 'l'homme moyen physique' and 'Ihomme moyen morale, 'both a physically average and a morally average construct...In formulating the idea of 'l'homme moyen, 'Quetelet is also providing a justification for 'les classes moyens.' With bourgeois hegemony comes scientific justification for moderation and middle-class ideology. The average man, the body of the man in the middle, becomes the exemplar of the middle way of life. ${ }^{82}$

According to Davis, the notion of the average or normal, paradoxically, became "a kind of ideal, a position devoutly to be wished. As Quetelet wrote, 'an individual who epitomized in himself, at a given time, all the qualities of the average man, would represent at once all the greatness, beauty and goodness of that being." "' stood everything that deviated from the statistical average (at either end of the bell curve) as 'error,' even when those traits were ones seen as positive- exceptional intelligence, height, etc. To solve this dilemma, Sir Francis Galton renamed the error curve, calling it the 'normal' curve, and revised the way in which it was graphed..$^{84} \mathrm{He}$ "created what he called an 'ogive,' which is 
arranged in quartiles with an ascending curve that features the desired trait as 'higher' than the undesirable deviation." " In this way, Galton succeeded in taking the normal towards the ideal-in reinstating the idea of the ideal, but now with an attendant imperative to actually aspire towards it. The fourth quartile, the 'top end' of the curve, became the most normal- "the new ideal of ranked order [became] powered by the imperative of the norm." ${ }^{\prime 86}$ Davis' discussion of statistics provides a powerful argument for understanding hegemonic masculinity through the 'normal-as-ideal.' From this perspective, hegemonic masculine embodiment is indeed impossible, because such a person would have to be exceptional in every possible trait (physical, moral, emotional, behavioural) that could be graphed. It is for this reason, I believe, that "the nondisabled stance, like the white stance [and, I am arguing, the masculine stance] is veiled. '[It] cannot be said quite out loud or it loses its crucial position as a precondition of vision." "' If If wat we are talking about when we say 'masculinity' (or white or 'able-bodied') is not the normal-as-average, but the normal-as-ideal, then we have arrived at an understanding of the discursive (and scientific) construction of masculinity. We must still ask, however, what the relationship is between this ideal and 'masculinity' as it is lived. If the average is 'powered by the ideal,' then we cannot separate gender as it is performed, from gender as it is idealized. I believe that Davis' discussion of the historical circumstances and scientific processes that produce the normal-ideal actually describes the exact moment of the coming into being of the phallus, as Jacques Lacan describes it. As the ultimate 'precondition of vision,' or the universal signifier, the phallus is, I am suggesting, what we already mean when we say 'masculinity.'

\section{The Phallus}

As a "culturally universal structure of signification," Judith Butler writes, the phallus "is nowhere fully instantiated in the real." ${ }^{8}$ Similarly,

ideal able-bodied identity can never, once and for all, be achieved. Able-bodied identity and heterosexual identity are linked in their mutual impossibility and in their mutual incomprehensibility-they are incomprehensible in that each is an identity that is simultaneously the ground on which all identities supposedly rest and an impressive achievement that is always deferred and thus never really guaranteed. ${ }^{89}$

The impossibility and incomprehensibility of the categories effects a "consolidation of hegemonic identities," a consolidation which, I am arguing, is the phallus. ${ }^{90}$ It should be clear, then, that I am understanding the phallus as truly universal-as governing not only "the relations between the sexes," but between all bodies." Following Daniel Boyarin, I am assuming that "the 
Freudian/Lacanian reading of the condition of lack [with respect to the phallus] as being figured in the discourse of a particular culture as castration is most powerfully diagnostic of the effects of this culture, but only if we remember to read this figuration as the product of a particular culture." ${ }^{.92}$ Indeed, I would wish to de-emphasize the relationship between castration and the phallus and to focus on the signification of the phallus and its relationship to (differential, embodied) lack, if only because the idea of castration, and indeed the term 'phallus' itself, can cause an inaccurate emphasis on sexual difference, or an understanding of this difference as prior to other differences. If, as Butler writes, "men are said to 'have' the Phallus, yet never to 'be' it, in the sense that the penis is not equivalent to that Law," and if "women are said to 'be' the Phallus in the sense that they maintain the power to reflect or represent the 'reality' of the self-grounding posture of the masculine subject, ${ }^{, 93}$ then it is in the position of the woman, of being the phallus, that masculinity is signified. The phallus "speaks in the Other," have been asking the other to speak, to reflect or represent masculinity through an understanding of its own lack, assuming, as DiPiero does, that "the identity in question cannot perform the taxonomically impossible task of defining itself." ${ }^{\circ}$ DiPiero, however, is speaking of whiteness, and notes that "white masculinity has asked those unlike itself to return to it an image of its identity." The "African American or Latino," he writes, is "conscripted to tell the white man who or what the latter is, and to know more about his identity than he himself apparently does. ${ }^{997}$ McRuer notes that the same process of reflection operates with respect to able-bodied or heterosexual identity: "the parallel structure of the [Oxford English Dictionary] definitions of ability and sexuality is quite striking ... to be able-bodied is to be 'free from physical disability,' just as to be heterosexual is to be 'the opposite of homosexual." "'98 Discursively, at least, the structure of difference and the way in which it signifies, remains the same. Which is to say that homosexual men, men of colour, Jewish men and disabled men are all put in the position of 'being' the phallus-of being women. They reflect the hegemonic ideal through a knowledge of their own lack, which is, at once, a knowledge of the ideal.

Boyarin writes that this

experience of a self doubling back on itself, observing itself, is psychoanalysis's primal encounter with the decentered self. [He] suggest[s] not that disadvantaged subjects-whether gay, female, colonized, black, or Jewish have a politically privileged access to 'truth,' but that their disadvantage is a condition of their access to such understanding" and calls this the "epistemological advantage of the "postcolonial subject' vis-à-vis the white male's imaginary possession of the phallus. ${ }^{99}$

As I have shown in my discussion of passing, however, this understanding 
is always fragmentary. The disadvantage (or lack), of the post-colonial subject is not only the 'condition of access,' it is also its limit. Or, to put it more simply, and in the context of masculinity: one can only know masculinity to the extent that one does not measure up to it. If, as I have also shown, no one can measure up-if complete hegemonic embodiment, at all times and in all contexts, is an impossibility - does that not put all men in the position of 'a self doubling back on itself,' with the attendant 'epistemological advantage,' insofar as they fail in living up to masculinity, at least some of the time? This, indeed, is what Lacan seems to be saying:

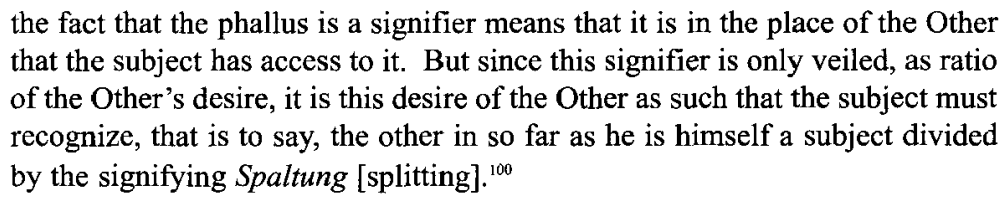
that the subject has access to it. But since this signifier is only veiled, as ratio of the Other's desire, it is this desire of the Other as such that the subject must recognize, that is to say, the other in so far as he is himself a subject divided by the signifying Spaltung [splitting]. ${ }^{100}$

We have seen that the signifier is veiled, as Lacan writes, precisely because what it can signify is limited by lack - because it is in ratio to desire. But Lacan is clearly suggesting that all subjects are split- that they are, as Boyarin might say, 'colonized' by the phallus. Lacan writes that "man cannot aim at being whole once .... his relation as subject to the signifier [has been marked]."101 I am suggesting, then, that masculinity, as it is lived, is a hybrid identity, defined by the "doubled consciousness" 102 of the post-colonial subject.

In suggesting that lived masculinity is a condition of doubled consciousness, I am suggesting that it is a constant negotiation between 'being' and 'having' the phallus. I am not suggesting that men can 'be' the phallus through an embodiment of maleness-- that the penis can be equivalent to the Law, as Butler said - but that they can, themselves, signify masculinity to the extent that they are split, to the extent of their own lack with respect to masculinity. By understanding embodied masculinity in this way, I am addressing Connell's suggestion that men are subordinated by other men as a result of hegemonic masculinity (or the phallus). In material terms this means, not only, that the black man will signify for the white man, that he will reflect the white man's hegemonic masculinity, and, thereby allow the white man to seem to 'have' the phallus, but that a shorter man can signify, can 'be' the phallus, for a taller man, or that a less athletic man can do the same for one who is more so. At the same time, these men may appear to 'have' the phallus in their relations with men who are further than them from the normal-ideal (whatever it may be in a given context or, rather, whatever aspect of it may be salient at a particular time), i.e. whose lack/desire with respect to the phallus is greater. In suggesting that one man can be the phallus for another; I am necessarily also suggesting that one man desires the other. The subject (the tall man, in this rather simplistic example) desires 
the Other (the short man) in order to have his 'masculinity' confirmed. His desire for the Other is a desire for the phallus, a desire to have the phallus, and it is only the presence of the Other's lack which makes this possible. I am not talking, here, about homosexual or homosocial desire, and any interpretation of it as such would fall victim to the tendency to leap to easy conclusions about what constitutes 'maleness' or 'masculinity.' The Other, in this context, is not masculine/male. In fact, Lacan's formulation does allow for a more nuanced understanding of sexual and, I would argue, all difference. Women are "those who, from a psychoanalytic perspective, are considered to be women, regardless of their biological / genetic makeup." 103 A "great many biological females turn out to have masculine structure, and a great many biological males turn out to have feminine structure."104 Of course this statement refers to the structuring of the subconscious by the phallus, for individual subjects, but I am suggesting that the phallus as universal signifier (of lack, of desire, of difference, of value) operates differentially and contextually in each relation between two people, and structures those relations. There is a way in which the relation I have used as an example can be understood as homosexual, but it is no more homosexual than it would be if the Other were a woman. A subject is always in the position of desiring the phallus, and therefore desiring the Other, and so it does not matter whether the Other is physically 'male' or 'female.' In fact, regarding women, Lacan writes, "it is in order to be the phallus ... that the woman will reject an essential part of her femininity ... It is for what she is not that she expects to be desired." is desired by the subject for her masculinity-the masculinity that she is able to be for the subject (or one might say reflect), as a result of her own lack. Let me be perfectly clear-the short man in my example is not 'less masculine' than the subject. He is not Masculine at all. He is Other. He is, as Fanon said, not a man.

I have given very simplistic examples in order to illustrate my argument of what might make a man 'be' the phallus in relation to one man, and 'have' the phallus in relation to another. It is worth remembering however, as I showed through the discussion of passing, that many factors contribute to the way in which masculinity is read, and that we cannot necessarily predict which kinds of lack will be salient in each context and what will be the determining factor in deciding whether a man 'has' the phallus with respect to another man. What my discussion should make clear is that Connell is wrong in suggesting that some men will reap the benefits of hegemonic masculinity, while others will be oppressed by it. As I have shown, it is possible (and likely) that a man will experience both benefits (to the extent that he seems to 'have' the phallus) and subordination (to the extent that he must 'be' the phallus), as a consequence of hegemonic masculinity. 


\section{Hybridity}

We are faced, still, with the problem that men can 'have' the phallus, at least in relation to an 'other' whose lack is greater than theirs. This is a problem, because it suggests that hegemonic embodiment actually is possible, if only relationally and contextually. Lacan writes, however, that there is an "intervention of a 'to seem' that replaces the 'to have," ${ }^{106}$ an intervention which Butler understands as "a necessary or presuppositional impossibility to any effort to occupy the position of 'having' the Phallus, with the consequence that both positions of 'having' and 'being' are, in Lacan's terms, finally to be understood as comedical failures." ${ }^{107}$ This means that masculinity is not split between lack/'being' the phallus on the one hand, and 'having' the phallus/hegemonic masculinity on the other. Instead, the split is between lack/'being' and disavowal/'seeming.' Halberstam's distinction between 'realness' and the 'real' should clarify the distinction between 'having' and 'seeming': realness "is not exactly a performance, not exactly an imitation, it is the way that people appropriate the real and its effects ... The real, on the other hand, is that which always exists elsewhere and as a fantasy of belonging." 108 It is for this reason that I would suggest that all masculinity, as it is lived, is a form of passing. I am not suggesting that men do not feel themselves to be male or masculine. Quite the contrary, I am understanding masculinity as similar to FTM passing, in that "FTMs and transmen feel they are being seen as their true selves in living, dressing and behaving as men,"109 yet may at once have an awareness of 'lack' and how it is being modified in order to project their 'true selves.' I would also like to return to Jewish passing, because Itzkovitz' exploration of the 'chameleonic Jew' is relevant here. If "the natural place of the Jew was in passing," as Itzkovitz wrote, I am suggesting that this is also the natural place of men/masculinity. This is not to say that success in 'seeming' or passing as hegemonically masculine (as the hegemonic body) is what determines the extent of one's masculinity - that would be a simple matter of conforming to an ideal. Rather, it is the relationship between lack and the performance of aspects of the hegemonic 'natural-ideal' that is important, because any successful 'seeming' is at once a disavowal of lack. The subject is still split. Regardless of how closely the ideal is approximated the self is still, to some extent, doubling back on itself, observing itself in relation to the hegemonic ideal. It is the very hybridity of passing, the result of colonization by the phallus, which defines lived masculinity.

It should not be imagined that my analysis of lived masculinity as passing, or as Lacan's 'seeming,' is a suggestion that hegemonic masculinity is experienced as false, or that the fact that "masculinity is built around an anxiety of insufficiency" 110 means that it is fragile, or any the less hegemonic. The "seeming' of masculinity does 'pass' as hegemonic, and the benefits of money, power etc. that accrue to individual bodies on that basis are material. In fact, it is the 
very 'seeming' which re-produces the hegemonic ideal. Stoltenberg writes that "people born with penises must strive to make the idea of male sexual identity personally real by doing certain deeds and actions that are valued and chosen ... we all keep striving to make the idea real." individual's need to feel personally 'real' as male/masculine--the individual's desire for 'realness,' as Halberstam would say. This 'striving,' however, does 'make the idea real,' insofar as it continually reproduces it. This assertion is not new-it draws on Butler's exploration of performativity and repetition in Gender Trouble. By placing this idea in the context of passing and what it has told us about masculinity and lack, however, I am seeking to elaborate the point a little. Insofar as we can deduce what is contained in the ideal hegemonic body (through an examination of individuals' lack with respect to it), I have shown that it is not only vast, but also fragmentary, internally contradictory and that it differs between times and contexts. As Demetriou writes, "the masculinity that occupies the hegemonic position at a given historical moment is a hybrid bloc that incorporates diverse and apparently oppositional elements." ${ }_{112}$ Therein lies its strength. Connell writes:

There is an ordering of versions of femininity and masculinity at the level of the whole society ... [but] the possibilities of variation, of course, are vastly greater. The sheer complexity of relationships involving millions of people guarantees that ethnic differences and generational differences as well as class patterns come into play. But in key respects the organization of gender on the very large scale must be more skeletal and simplified than the human relationships in face-to-face milieux. The forms of femininity and masculinity constituted at this level are stylized and impoverished. Their interrelation is centred on a single structural fact, the global dominance of men over women. ${ }^{113}$

Hegemonic masculinity, I am suggesting, is not at all 'stylized and impoverished'; on the contrary, it is rich and diverse. Moreover, I have shown that the subordination of 'ethnic,' 'generational,' and 'class' differences to sex/gender difference is not only fallacious, but also does not aid in our understanding of sex/gender. We cannot, with respect to the hegemonic body/normal-ideal, attempt to piece out, in a pseudo-scientific way, one area of inquiry and expect to draw any adequate conclusions. The 'single structural fact' of the global dominance of men over women can, based on my examination of masculinity, just as easily be re-cast as the single structural fact of the global dominance of white over black, able-bodied over disabled, or rich over poor. The strength or 'hegemony' of the ideal lies exactly in its ability to signify, which is to say, in its ability to differentiate and, more importantly, to rank or assign value to any body, and to any two bodies in relation to each other. This understanding of the hegemonic ideal brings us back to how repetition re-produces the ideal and makes it real. It also explains why it should be that the hegemonic ideal is "a 
symptomatic reply to cultural demands, not ... a self-generating ahistorical entity somehow able endlessly to reproduce itself." 114 We cannot predict, with any accuracy, what the outcome of differentiation or signification, based on the hegemonic ideal will be. This is because the ideal is "in a constant process of negotiation, translation, hybridization, and reconfiguration." 15 It is also because the relationship between lack, and the way in which an individual compensates for it, is not always direct and because the aspects of hegemonic or 'other' identity that are salient in each individual body are contextual. What I mean is that the benefits of 'seeming' to be hegemonically masculine do not always accrue to individual bodies in predictable ways. This, DiPiero writes, is why "white males are so often angry [they are] sustaining the contradiction between how the culture defines them and how they experience their lives." When benefits do not accrue to individual (white, male, middle-class, able-bodied, heterosexual) bodies, there is always an aspect of the hegemonic ideal we can point to and say 'they didn't measure up,' especially because that ideal is internally contradictory. The failure of individuals, then, reflects no failure onto the hegemonic ideal. On the other hand, when a body (despite its 'other' status in terms of race, class, etc.) does experience great (political, economic, artistic, intellectual) success, there is always an aspect of the hegemonic ideal into which we can slot them. We can say they had exceptional strength of character, great perseverance and so forth (in short, that they succeeded, as we saw in the case of Fanon, because they were 'really' white, on the 'inside'). The fact that the hegemonic ideal can change, then (that it can sometimes look black, for example) is a result of the individual differences in the bodies which repeat or perform it. Whether the changes in the hegemonic ideal actually occasion any real positive effects, any material difference in the way that power is distributed (even if it occasionally defies our expectations of to whom it should be distributed), is a subject for another paper. For the purposes of this paper, however, it should suffice to note that it is entirely possible that the 'hybridity' of the hegemonic ideal only "ensure[s] the reproduction of patriarchy." 117

In conclusion, I would like to consider how to proceed with masculinity studies. There is, at least in western culture, only one masculinity. That it is hybrid and changes over time does not alter its structure. Its relationship to bodies and its ability to signify remains the same. We would also do well to keep in mind that masculinity is a hegemonic ideal, that it is at once the signifier of race, class, sex, and ability, and that any attempt to analyze one aspect without reference to the others obscures the processes of differentiation, signification, and the distribution of power as they relate to all bodies. This kind of constant vigilance with respect to difference may seem like a daunting task, but I think we can address it by asking different questions. From the perspective of studying literature or film (if only because this paper is being written in an English department), I think we should focus on the relationship between bod- 
ies and the salience of lack in masculinity studies. We might ask, who seems to embody the ideal masculinity in a given text, and why? Is he the ideal in every context, and in relation to every other person in the text? Is there someone who seems to fall short of hegemonic masculinity? What does he lack? How does he compensate for this lack? Is he hegemonically masculine in some contexts, but not in others, and why? Which aspects of hegemonic masculinity are most salient or important in the text? What kinds of power are distributed on the basis of this version of hegemonic masculinity? Is power distributed differentially across contexts, and for what reason? What is the relationship between behaviour and the body? Does one inform the other? Is the behaviour at odds with our expectations of that particular body in that particular context? How does the behaviour change our reading of the body, and vice versa? This is by no means an exhaustive list of questions and, although I have framed them in relation to literary studies, I see no reason why these questions could not be taken up in the context of sociological studies on masculinity.

Finally, I would suggest that we limit our use of the term 'masculinities.' It is, as I have shown, not at all useful in considering 'masculinity' in western culture, because there is only one masculinity. I am also unconvinced of the term's usefulness for cross-cultural work. I am by no means suggesting that the expectations of men's behaviour in all cultures be studied in relation to a western, hegemonic ideal; instead I think we should keep in mind that what we are studying when we study the behaviour of men in other cultures may not be masculinity at all. The behaviour exhibited by men may have much more to do with their age, their class, their occupation, their situation within their family, that family's relationship to the community etc., than the 'fact' that they are 'men.' It is confusing, not to mention Euro-centric, to discuss 'masculinities' with respect to people whose behaviour may be subject to an entirely different structure of signification. This is a call for greater vigilance in cross-cultural work through attention to culturally specific systems of signification. Even in postcolonial work, where the legacy of colonialism has left a trace of the phallus on a prior system of signification we should remember that these are not necessarily instances of two versions of 'masculinity' bumping up against each other, but masculinity bumping up against something else entirely. Ultimately, we would do well to remember that 'masculinity' is not a construct that describes the behaviour of men. It is a culturally specific term, with a specific, western ontology in studies of biological difference.

Notes

1. Jeff Hearn, "Is Masculinity Dead? A Critical Account of the Concepts of Masculinity and Masculinities," in Understanding Masculinities: Social Relations and Cultural Arenas, ed. M. Mac an Ghaill (Milton Keynes: Open University Press, 1996), 203. 
2. Kenneth Clatterbaugh, "What is Problematic About Masculinities?" in Feminism \& Masculinities, ed. Peter Murphy (New York: Oxford University Press, 2004), 201.

3. Hearn, 214.

4. Clatterbaugh, 209.

5. Ibid., 211.

6. Frantz Fanon, Black Skin, White Masks (New York: Grove Press, Inc., 1967).

7. Daniel Boyarin, "What Does a Jew Want? or, The Political Meaning of the Phallus," in The Masculinity Studies Reader, eds. Rachel Adams and David Savran (Oxford: Blackwell Publishers, 2002); Sander L. Gilman, The Jew's Body (New York: Routledge, 1991).

8. Clatterbaugh, 200.

9. Judith Butler, Undoing Gender (New York: Routledge, 2004).

10. Anne Fausto-Sterling, Sexing the Body (New York: Basic Books, 2000).

11. Alice Domurat Dreger, Hermaphrodites and the Medical Invention of Sex (London: Harvard University Press, 1998).

12. Judith Halberstam, Female Masculinity (Durham: Duke University Press, 1998).

13. It is especially illustrative in the context of masculinity/maleness to consider that intersexual surgery is performed not only on infants with a chromosomal or hormonal abnormality, but also on infants who are biologically male, but who fail to approximate a morphological standard of maleness. As Anne Fausto-Sterling (2000) describes in detail, boys who are born with a penis deemed (by the attendant surgeon) not sufficiently long for heterosexual penetrative intercourse, have that organ shortened to the length of a clitoris and, after further sexual reassignment surgery, are raised as girls. This is a material example of the way in which a male body can fail to live up to maleness, and more importantly, of how the borders of maleness are policed.

14. Clatterbaugh, 200.

15. Margaret Wetherell and Nigel Edley, "Negotiating Hegemonic Masculinity: Imaginary Positions and Psycho-Discursive Practices," Feminism \& Psychology 9, no. 3 (1999); Demetrakis Demetriou, "Connell's Concept of Hegemonic Masculinity: A Critique," Theory and Society 30 (2001); Susan A. Speer, "Reconsidering the Concept of Hegemonic Masculinity: Discursive Psychology, Conversation Analysis, and Participants' Orientations," Feminism \& Psychology 11, no. 1 (2001); Clatterbaugh, 2004.

16. R.W. Connell, Masculinities (Berkeley: University of California Press, 1995), 77.

17. Ibid.

18. Wetherell and Edley, 337.

19. Ibid, 335 .

20. Connell, Masculinities, 77.

21. Connell, Masculinities, 78-79.

22. King-Kok Cheung, "Art, Spirituality and the Ethic of Care: Alternative Masculinities in Chinese American Literature," in Masculinity Studies \& Feminist Theory, ed. Judith Kegan Gardiner (New York: Columbia University Press, 2002); Don Kulick, "The Gender of Brazilian Transgendered Prostitutes," in The Masculinity Studies Reader, eds. Rachel Adams and David Savran (Oxford: Blackwell Publishers Ltd., 2002); Alan Bray, "Homosexuality and the Signs of Male Friendship in Elizabethan England," in Queering the Renaissance, ed. Jonathan Goldberg (Durham: Duke 
University Press, 1994); Revathi Krishnaswamy, Effeminism: The Economy of Colonial Desire (Ann Arbor: University of Michigan Press, 1998).

23. Erving Goffman. Cited in Michael Kimmel, "Masculinity as Homophobia: Fear, Shame, and Silence in the Construction of Gender Identity," Theorizing Masculinities, eds. Harry Brod and Michael Kaufman (London: Sage Publications, 1994), 125.

24. Wetherell and Edley, 351.

25. Ibid., 343.

26. Clatterbaugh, 203.

27. Sara Ahmed, "She'll Wake Up One of These Days and Find She's Turned Into a Nigger:' Passing Through Hybridity," Theory, Culture \&Society 16, no.2 (1999): 98.

28. Elaine K. Ginsberg, "Introduction: The Politics of Passing," in Passing and the Fictions of Identity, ed. Elaine K. Ginsberg (Durham: Duke University Press, 1996), 3. 29. Ibid, 2-3.

30. Amy Robinson, "Passing and Communities of Common Interest," Critical Inquiry 20 (1994): 716.

31. Brooke Kroeger, Passing: When People Can't Be Who They Are (New York: Public Affairs, 2003), 8.

32. Fanon, 8 .

33. Ibid., 18.

34. Ibid., 44.

35. Ibid., 63.

36. Ibid., 38.

37. Roger Bastide. Quoted in Richard Dyer, White (New York: Routledge, 1997), 64.

38. Fanon, 69.

39. Sander L. Gilman, Jewish Self-Hatred: Anti-Semitism and the Hidden Language of the Jews (Baltimore: Johns Hopkins University Press, 1986), 246.

40. Ibid., 245.

41. Ibid., 74-75.

42. Abraham Myerson. Quoted in ibid., 303.

43. Kate Bornstein, My Gender Workbook (New York: Routledge, 1998), 146.

44. Gilman, Jewish Self-Hatred: Anti-Semitism and the Hidden Language of the Jews; Gilman, The Jew's Body.

45. Sander L. Gilman. Quoted in Dyer, 54.

46. Daniel Itzkovitz, "Passing Like Me: Jewish Chameleonism and the Politics of Race," in Passing: Identity and Interpretation in Sexuality, Race, and Religion, eds. Maria Carla Sanchez and Linda Schlossberg (New York: New York University Press, $2001), 42$.

47. Ibid.

48. Ibid., 43 .

49. Ibid., 45.

50. Brooke Kroeger, Passing: When People Can't Be Who They Are (New York: Public Affairs, 2003), 8.

51. Andy, "FTM Passing Tips," (http://www.geocities.com/ftmPass/passing.html).

52. Ibid.

53. Ibid.

54. Ibid. 
55. Judith Halberstam, "Telling Tales: Brandon Teena, Billy Tipton, and Transgender Biography," in Passing: Identity and Interpretation in Sexuality, Race, and Religion, eds. Maria Carla Sanchez and Linda Schlossberg (New York: New York University Press, 2001), 32.

56. Ginsberg, 2.

57. Kroeger, 104.

58. Andy, "FTM Passing Tips" (http://www.geocities.com/ftmPass/passing.html)

59. Ibid.

60. Ibid.

61. Hearn notes, for example, that masculinity "means quite different things...as it shifts between the worlds of the infant, of growing up, of adult life and old age and dying." Hearn, 210.

62. Dean Kotula, The Phallus Palace (Los Angeles: Alyson Publications, 2002), 60.

63. Aristotle. Quoted in Rosemarie Garland Thomson, Extraordinary Bodies: Figuring Physical Disability in American Culture and Literature (New York: Columbia University Press, 1997), 19-20.

64. Harlan Hahn "Advertising the Acceptably Employable Image: Disability and Capitalism," in The Disability Studies Reader, ed. Lennard J. Davis (New York: Routledge, 1997), 181. Hahn discusses a 1921 advertisement for Kotex. The initial draft of the ad had included men, but it was "withdrawn by the [advertising] agency, because they felt that men should not be depicted in an intimate discussion of feminine hygiene. Subsequently, another version containing three nurses and a soldier in a wheelchair was published as the first advertisement for this product in 1921."

65. Lennard J. Davis, Enforcing Normalcy: Disability, Deafness and the Body (New York: Verso, 1995), 13.

66. Michelle Fine and Adrienne Asch. Quoted in ibid., 10.

67. Candice M. Lee, "From 'Passing' to 'Coming Out'," Ragged Edge Online Sept / Oct 2003 (http://www.raggededgemagazine.com/0903/0903ft2.html)

68. Ibid.

69. Davis, 92-99.

70. Ibid., 97.

71. Ibid., 93.

72. Ibid., 13-14.

73. Perry N. Halkitis, "Masculinity in the Age of AIDS: HIV-Seropositive Gay Men and the "Buff Agenda"," in Gay Masculinities, ed. Peter Nardi (London: Sage Publications, Inc., 2000).

74. Robert McRuer, "Compulsory Able-Bodiedness and Queer / Disabled Existence," in Disability Studies: Enabling the Humanities, eds. Sharon L. Snyder, Brenda Jo Brueggemann, and Rosemarie Garland Thomson (New York: The Modern Language Association of America, 2002), 94.

75. Dyer, 57.

76. Ibid., 51-52.

77. Thomas DiPiero, White Men Aren't (Durham: Duke University Press, 2002), 16.

78. Nancy Leys Stepan, "Race and Gender: The Role of Analogy in Science," Isis 77, no. 2 (1986): 263-264.

79. Ibid., 262. 
80. Davis, 24-25.

81. "The word 'normal' as 'constituting, conforming to, not deviating or differing from, the common type or standard, regular, usual' only enters the English language around 1840. Likewise, the word 'norm,' in the modern sense, has only been in use since around 1855, and 'normality' and 'normalcy' appeared in 1840 and 1857 respectively." Ibid., 24.

82. Ibid., 26-27.

83. Adolphe Quetelet. Quoted in ibid., 27.

84. Figure 1 shows the original 'error' curve, Figure 2 shows Galton's new 'normal' curve. Ibid., 34.

85. Ibid., 33-34.

86. Ibid., 34.

87. Donna Haraway. Quoted in Simi Linton, Claiming Disability: Knowledge and Identity (New York: New York University Press, 1998), 14.

88. Judith Butler, Gender Trouble (New York: Routledge, 1990), 44.

89. McRuer, 93.

90. Ibid., 94.

91. Jacques Lacan, Ecrits: A Selection (New York: W.W. Norton \& Co., 1977), 289.

92. Daniel Boyarin, "What Does a Jew Want? Or, The Political Meaning of the Phallus" in The Masculinity Studies Reader, eds. Rachel Adams and David Savran (Oxford: Blackwell Publishers Ltd., 2002), 181.

93. Butler, Gender Trouble, 46.

94. Jacques Lacan, Feminine Sexuality: Jacques Lacan and the Ecole Freudienne, eds. Juliet Mitchell and Jacqueline Rose (New York: W.W. Norton \& Co., 1982), 79.

95. DiPiero, 3.

96. Ibid., 20.

97. Ibid., 7.

98. McRuer, 91.

99. Boyarin, 279.

100. Lacan, Ecrits: A Selection, 288.

101. Lacan, Feminine Sexuality: Jacques Lacan and the Ecole Freudienne, 81-82.

102. Boyarin, 279.

103. Bruce Fink, The Lacanian Subject: Between Language and Jouissance (Princeton: Princeton University Press, 1995), 107.

104. Ibid., 108.

105. Lacan, Feminine Sexuality: Jacques Lacan and the Ecole Freudienne, 84.

106. Lacan, Ecrits: A Selection, 239.

107. Butler, Gender Trouble, 46.

108. Judith Halberstam, "Telling Tales: Brandon Teena, Billy Tipton, and Transgender Biography," 17.

109. Jason Cromwell, Transmen \& FTMs: Identities, Bodies, Genders \& Sexualities (Chicago: University of Illinois Press, 1999), 39.

110. DiPiero, 9.

111. John Stoltenberg, Refusing to be a Man: Essays on Social Justice (New York:

UCL Press, 2000), 28.

112. Demetriou, 349. 
74 Bredenkamp

113. R.W. Connell, Gender and Power (Stanford: Stanford University Press, 1987),

183.

114. DiPiero, 3.

115. Demetriou, 355.

116. DiPiero, 3.

117. Demetriou, 337. 